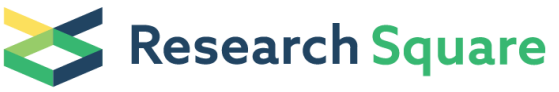

\section{Apoptosis Induced by Melatonin and Vitamin D3 in MCF-7 Breast Cancer Cell Line by Upregulating the Gene Expression of P53}

\author{
Abir Alamro \\ King Saud University \\ Nora Alkeraishan \\ King Saud University \\ Manal AlMalky \\ King Saud University \\ Amani Alghamdi \\ king Saud University \\ Nasser M Al-Daghri \\ King Saud University \\ Samina hyder Haq ( $\nabla$ shaq@ksu.edu.sa ) \\ King Saud University https://orcid.org/0000-0002-8617-3767
}

Research article

Keywords: breast cancer, MCF-7, p53, apoptosis, gene expression, protein expression

Posted Date: December 31st, 2020

DOI: https://doi.org/10.21203/rs.3.rs-137144/v1

License: () (1) This work is licensed under a Creative Commons Attribution 4.0 International License.

Read Full License 


\section{Abstract}

Background: P53 was identified as the first tumor suppressor gene actively involved in numerous cellular mechanisms such as initiating DNA repair mechanisms, apoptosis, and cell cycle arrest. More than $50 \%$ of all human cancers have a mutated nonfunctional p53 expression. Breast cancer (BC) is one of the leading causes of mortality in females and mutated p53 is documented to be the causative agent in only $20 \%$ of them. However, a mutation in p53 in BC results in a more aggressive form of cancer which is more resistant to conventional therapies. Recently multiple clinical trials suggested that the combined use of melatonin and vitamin D3 can slow down the growth of breast cancer cells. The genetic and molecular mechanisms through which these compounds initiate the cancerous cells to apoptosis or cell cycle arrest is still not fully understood. This study aims to investigate the effect of melatonin, vitamin D3, and their combined treatment on the gene expression of P53 in MCF-7 breast cancer cell line.

Methods: The optimum treatment dose for melatonin and vitamin D3 were found by MTT and LDH assay. MCF-7 breast cancer cell line were treated with this optimum concentration, and studied the gene expression of p53 by RTPCR and concomitant protein expression by western blots analysis

Results: This study indicated that $5 \mathrm{nM}$ melatonin, $0.5 \mathrm{nM}$ vitamin $\mathrm{D} 3$, and their combined treatment inhibited the proliferation of MCF-7 breast cancer cells and caused apoptosis by upregulating the p53 gene expression $(2$-fold) and significant increase $(p<0.001)$ in p53 protein expression.

Conclusion: Treatments with melatonin and vitamin D3 were found to have anti-cancerous effect and could potentially prove to be the ideal natural adjuvant therapy for the treatment of breast cancer.

\section{Introduction}

Breast cancer (BC) is the most common cancer in women and it has been reported that in Saudi Arabia, it is one of the leading causes of death after cardiovascular disease[1]. Recently several studies have shown that the disruption of circadian rhythm would increase the risk of breast cancer [2]. Studies related to the disruption of melatonin's circadian profile by exposure to light at night time (LAN) has been described to play an important role in the initiation, promotion, and progression of breast cancer [3]. Melatonin ( $\mathrm{N}$-acetyl-5-methoxy tryptamine) is an indolic compound secreted primarily by the pineal gland of humans, which is thought to control sleep, is directly related to circadian activity through the supranuclear nucleus (SCN) in the brain. Melatonin is capable of binding to cell surface receptors (MT1 and MT2), cytosolic sites (calmodulin), and directly to nuclear DNA binding sites. It can exert its anticancer effect primarily through receptor-dependent and receptor-independent mechanisms [4].

Moreover, in the past decade, scientific advances revealed the extra-skeletal pleiotropic effect of vitamin D on human health and related clinical conditions [5-7]. Of particular interest, is the inverse relationship between serum vitamin $D$ level and breast cancer development, recurrence, and mortality [8-10]. Although the relationship between vitamin $\mathrm{D}$ and breast cancer remains unclear, multiple studies had demonstrated the anti-proliferative effect of vitamin $D_{3}$ for different cancer cells and had found an in 
vitro effect of 1,25-(OH)2D3 on breast cancer cell lines including cell-cycle arrest and induction of differentiation and apoptosis $[9,11,12]$. Studies revealed that vitamin $D$ increases the genes involved in DNA damage repair such as p53, proliferating cell nuclear antigen (PCNA), and breast cancer type 1 susceptible protein (BRACA1) in breast cancer cells [13].

In the present study, the effect of melatonin, Vitamin $\mathrm{D}$, and their combined effect on the proliferation and gene expression of p53 in MCF-7 breast cancer cell line were studied. MCF-7 cells were grown for $24 \mathrm{~h}$ and $48 \mathrm{~h}$ in the presence of varying concentrations of melatonin and vitamin D3 to estimate the optimum concentration of their treatments and further used these optimum doses to study the gene and protein expression of p53. Both MTT and LDH assays were used to validate the optimum concentrations.

\section{Materials And Methods 2.1 Cell culture}

Breast cancer cell line MCF-7 (ATCC $®$ HTB22TM) obtained from (ATCC, USA) was cultured in Dulbecco's Modified Eagle Medium (DMEM) supplemented with 10\% Fetal Bovine Serum (FBS) and 1\% penicillin/streptomycin. Cells were grown as an adherent monolayer in T-25 or T-75 culture flasks and 6well plates or 96-well plates (according to the type of the experiment) at $37^{\circ} \mathrm{C}$ humidified environment of $5 \% \mathrm{CO}_{2}$. The medium was changed every third day. At confluence, cells were sub-cultured after removal with $0.05 \%$ trypsin-EDTA. Cell viability was assessed with trypan blue

\subsection{MTT cell proliferation assay}

To find the optimum concentration of melatonin and vitamin D3 for growth inhibition of breast cancer cell line MCF-7, cells were plated onto 96 well plates and exposed to different concentrations of melatonin $(1,5$, and $10 \mathrm{nM})$ and vitamin $\mathrm{D} 3(0.5,1$, and $10 \mathrm{nM})$ for different periods (24 and 48 hours) at $37^{\circ} \mathrm{C}$ in a $\mathrm{CO}_{2}$ incubator. $10 \mu \mathrm{l}$ of MTT reagent $(5 \mathrm{mg} / \mathrm{mL}$ in PBS) was added to each well and further incubated for $3-4$ hours at $37^{\circ} \mathrm{C}$. After that, the medium was removed and the formed formazan crystals were solubilized by adding $100 \mu \mathrm{l}$ of isopropanol in $0.04 \mathrm{HCL}$ per well for $30 \mathrm{~min}$ at $37^{\circ} \mathrm{C}$ in a $\mathrm{CO}_{2}$ incubator. The absorbance was read at $540 \mathrm{~nm}$ using the BioTek ELx800 absorbance microplate reader (Fisher Scientific, USA). The optical density (OD) value was subjected to sort out the percentage of cell viability by using the following formula: Cell viability $(\%)=(O D$ value of experimental samples / OD value of experimental control sample) $X 100$. The treatment groups were compared with the control group and the results were expressed as a percentage of viable cells.

\subsection{Lactate Dehydrogenase Assay (LDH)}

LDH assay was performed using Lactate Dehydrogenase Assay kit ab102526 (Abcam, USA) according to the manufacturer's protocol. MCF-7 cells were seeded in a 96-well plate at a density of $1 \times 10^{4} \mathrm{cell} / \mathrm{s} /$ well and allowed to adhere for 24 hours incubated at $37^{\circ} \mathrm{C}$. After 24 hours of incubation, the supernatant was collected and transferred to a new tube and kept on ice. Colorimetric kinetic determination of lactate 
dehydrogenase activity in the cell lysate was measured using microplate reader in kinetic mode at $450 \mathrm{~nm}$, every $2-3 \mathrm{~min}$, for at least $30-60 \mathrm{~min}$ at $37^{\circ} \mathrm{C}$ protected from light.

\subsection{RNA extraction and cDNA synthesis}

Total RNA was isolated after $48 \mathrm{~h}$ treatment with vitamin D3 $0.5 \mathrm{nM}$, melatonin $5 \mathrm{nM}$, and combined treatment of both from cell lysate by using the RNA easy kit (Qiagen, Germany) according to the manufacturer's protocol. Total RNA (2ug measured by spectrophotometry to $260 \mathrm{~nm}$ ) was reverse transcribed to cDNA using the SuperScript Vilo cDNA Synthesis Kit (Thermo Fisher, USA).

\subsection{Real-Time Polymerase Chain Reaction (RT-PCR)}

Quantitative analysis of specific mRNA expression was performed by RT-PCR by subjecting the resulting CDNA to PCR amplification using a 96-well PCR plate in CFX96 ${ }^{\text {TM }}$ Real-Time System (BIO-RAD, USA) using KAPA SYBER FAST Universal qPCR Kit (KAPA BIOSYSTEM, USA). The primers sequence for $p 53$ and the housekeeping gene, GAPDH is given in table 1 .

Table 1. Primer sequences for the targeted p53 genes

\begin{tabular}{|lll|}
\hline \multicolumn{2}{|c|}{ Forward } & Reverse \\
\hline GAPDH & 5 '-CTTTTGCGTCGCCAGGTGAA-3 ' $^{\prime}$ & 5'-AGGCGCCCAATACGACCAAA-3' \\
\hline P53 & 5'-CCTGGATTGGCAGCCAGACT-3 ' & 5'-TTCCTGACTCAGAGGGGGCT-3 ' \\
\hline
\end{tabular}

\subsection{Preparation of cellular extracts and Western blot (WB) analysis}

After the required treatment, cells were washed with PBS and scraped in RIPA buffer supplemented with protease inhibitors. The protein content of cell lysate was determined using the Bicinchoninic Acid Protein Assay Kit (Sigma-Aldrich, USA). For immunoblot analysis, cell lysate was separated on 10\% SDS-PAGE gels. Protein from the gel was electrophoretically transferred to PVDF membrane in a 1X transfer buffer containing Tris-HCL, glycine, methanol, and $20 \%$ SDS at $13 \mathrm{~V}$ for $27 \mathrm{~min}$. Protein blots were blocked overnight at $4^{\circ} \mathrm{C}$ in a solution containing $5 \%$ non-fat dry milk powder in Tris-buffered saline (TBS) solution ( $\mathrm{NaCl}$, Tris-base, $\mathrm{pH}$ 7.6). The blocking solution was removed, and the blots were washed in a wash buffer (TBS) followed by $2-3 \mathrm{~h}$ incubation at $4^{\circ} \mathrm{C}$ with monoclonal primary mouse antibody against tubulin and $p 53$. The primary antibody was removed, and blots were rinsed three times with a wash buffer TBST ( $\mathrm{NaCl} /$ Tris-base, $0.1 \%$ Tween, $\mathrm{pH} 7.6$ ), followed by incubation with peroxidaseconjugated Goat anti-mouse IgG (1:1000) at room temperature for $2 \mathrm{~h}$. The bands were visualized by LICOR Bioscience (Lincoln, Nebraska, USA) using the enhanced chemiluminescence method according to the manufacturer's instruction (Abcam, Canada).

\subsection{Statistical Analysis}


Results were presented as mean \pm SD and analyzed using Two-way ANOVA analysis. Microsoft excel 2010 and GraphPad Prism 6 software (GraphPad Software, San Diego, CA, US) was used.

\section{Results}

\subsection{Effects of Melatonin and Vitamin D on the Cellular Proliferation of MCF-7.}

The effect of different doses of vitamin D and melatonin was evaluated by MTT assay. MCF-7 cells were grown for $24 \mathrm{~h}$ and $48 \mathrm{~h}$ in the presence and absence of varying doses of melatonin (1 to $10 \mathrm{nM}$ ) and Vitamin D (0.5 to10nM). We did not find a significant difference in cell viability after $24 \mathrm{~h}$ treatments. However, after $48 \mathrm{~h}$ in culture, $0.5 \mathrm{nM}$ vitamin $\mathrm{D}$ and $5 \mathrm{nM}$ melatonin treatments caused a significant decrease in cell proliferation as shown in (Fig. 1A).

Therefore, these concentrations were used in all the other later studies for gene and protein expression.

\subsection{Effect of Melatonin and Vitamin D on LDH Enzyme Assay.}

We observed an increased amount of LDH activity in the control of MCF-7 cells after $24 \mathrm{~h}$ and $48 \mathrm{~h}$ in culture as expected and reported in other studies that cancer cells have high LDH activity. However, when these cells were treated with different doses of vitamin D3 and melatonin we could see the therapeutic effect of these compounds more pronounced at $48 \mathrm{~h}$ in culture, where $0.5 \mathrm{nM}$ vitamin D3 and $5 \mathrm{nM}$ of melatonin caused a marked reduction in the amount of LDH enzyme levels, which supported our earlier finding with MTT assay (Fig. 1B).

\subsection{Effect of Vitamin D and melatonin on mRNA of p53.}

MCF-7 cells treated with Vitamin D3 $0.5 \mathrm{nM}$, Melatonin $5 \mathrm{nM}$ alone or in combination for $48 \mathrm{~h}$, showed an increased expression of the mRNA levels of $p 53$. We found that the mRNA levels were increased to double as compared to control (1 fold in control, 2-fold with Vitamin D3, and 2.17-fold with melatonin). Their combined treatment also exhibited an increased mRNA expression (1.98-fold) as compared to the control as shown in Fig. 2.

\subsection{Effects of Vitamin D and Melatonin on Protein Expression of p53}

The protein level of the pro-apoptotic gene (p53) in response to $48 \mathrm{~h}$ treatment of MCF-7 cells was determined by Western blot analysis. The results of western blot supported the earlier p53 gene expression findings. Control cells without any treatment showed no p53 protein expression as cancer cells were shown to downregulate P53 protein expression to survive and proliferate. However, when these cells were treated with Vitamin D3, there was an upregulation of p53 protein expression as shown as a light band appearing in the WB. The effect of treatment with Melatonin on MCF-7 cells for $48 \mathrm{~h}$ was more 


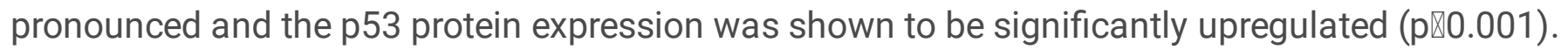
However, the combined treatment exhibited positive effect on the protein expression of p53 as shown in Fig. 3.

\section{Discussion}

Breast cancer (BC) has a great impact on the health of women worldwide as it affects more than 1.3 million women each year and accounts for about $14 \%$ of cancer-related deaths. Over the past two decades, significant research efforts have been initiated towards the role of melatonin and vitamin D3 in the etiology of cancer. The exact cellular and genetic mechanisms through which these compounds confer their therapeutic effect is still very ambiguous. In this study, we tried to study the therapeutic effect of vitamin D3, melatonin on MCF-7 breast cancer cell line and tried to unravel the molecular and cellular pathways that could initiate apoptosis of the cancer cells in-vitro.

The results presented demonstrate that melatonin and vitamin D3 have an optimum therapeutic dosage at $48 \mathrm{~h}$ of $5 \mathrm{nM}$ and $0.5 \mathrm{nM}$ respectively. Both MTT and LDH assay supported the therapeutic efficacy of these treatments. In most of the cytotoxic studies, MTT had been considered as the single most reliable parameter to measure cellular metabolic activity, and indicator of cellular viability, proliferation, and cytotoxicity. However, we tried to explore more at the metabolic status of these cells as a result of treatments by performing LDH assay. As, the role of the LDH enzyme in the initiation, promotion, and progression of cancer cells was well documented [14]. The cancer cells rely mostly on glycolysis with a huge intake of glucose and lactate production, the phenomena known as the Warburg effect. Lactate production in glycolysis contributes largely to malignant progressions, like replenishing NAD + for glycolysis, lowering $\mathrm{pH}$ for invasion/n and triggering immune escape, and above all the hypoxia conditions support angiogenesis. Lactate dehydrogenase A (LDH) converts pyruvate to lactate and activation of LDH enzyme is closely related to diverse cancers. We observed an increased amount of LDH activity in the control of MCF-7 cells after $24 \mathrm{~h}$ and $48 \mathrm{~h}$ in culture as expected and reported in other studies that cancer cells have high LDH activity [15]. However, the treatment of vitamin D3, melatonin, and in their combination resulted in significant downregulation of LDH enzyme levels indicating the therapeutic potential of these drugs.

Our data showed that melatonin and vitamin D3 were involved in the regulation of cell proliferation and apoptosis and suggested that this action could be, at least in part, ascribed to the increased expression of p53. Previous studies had shown that melatonin combined with D3 synergistically inhibits the proliferation of MCF-7 cells [16]. The human homolog of the mouse double minute gene 2 (MDM2) is known to be usually overexpressed in different types of malignancies [17]. MDM2 can ligate p53 protein by its E3 ubiquitin ligase, and the resulting ubiquitinated p53 can be transferred to the cytoplasm to be degraded by proteinases. Thus the main role of MDM2 in the progression of cancer is to silence the tumor suppresser activity of p53. The MDM2 gene is itself transcriptionally activated by p53in a regulatory loop [18]. Several therapeutic strategies have been suggested to disrupt the p53-MDM2 interactions including the use of small peptides [19] and inhibitors of ubiquitin ligase [20]. Recent studies 
on natural products as a safe therapeutic in the treatments of various forms of cancers have reported that melatonin and vitamin D3 could reduce MDM2 levels or to hinder the p53-MDM2 interactions [21, 22]. Enhanced production of p53 as a result of treatments is one of the goals as well as promising prognosis and indicators of the success of the treatments.

The cytotoxic effect of the melatonin in-vitro model of breast cancer in MCF-7 cells was exhibited due to the accumulation of cells in the Go/G1 phase of the cell cycle or delaying the progression to the $S$ phase of the cell cycle [23]. This decreased cell proliferation was also accompanied by significantly increased gene expression of p53in other studies[24].

The quantitative gene expression studies using RT-PCR exhibited a significant upregulation of p53 with the vitamin D3, melatonin, and their combined treatments. Moreover, concomitant results were shown for protein expression analysis by Western blot, demonstrating that in control cells, there was no signal for p53 protein expression but cells treated with vitamin D3 showed a light band indicating the upregulation of $p 53$, whereas melatonin treatment showed a very high signal for $p 53$ protein expression. This effect was very significant and important for this study as it indicated that melatonin alone has a supportive upregulating effect on the P53 gene and protein expression as compared to vitamin D3 alone or in its combination. The exact molecular mechanism and the involvement of MDM2 gene expression concerning p53 expression with the treatment of vitamin D3 and melatonin warrants further investigation and opens up new avenues for future research. In this study, both of the compounds had shown to have a pro-apoptotic effect on breast cancer cells in-vitro and also indicated that both of them might have exhibited these properties through different molecular and biochemical mechanisms.

\section{Conclusion}

The downregulation of p53 gene expression and being resistant to chemotherapy is the major challenge to overcome in the treatment of breast cancer. More than $50 \%$ of all human cancers have a mutated or nonfunctional p53 expression with a very poor prognosis. Melatonin and vitamin D3 are known antioxidants and exhibited encouraging results in the treatment of various forms of malignancies. The present study further emphasized the anti-cancerous role of melatonin, vitamin D3, and their combined treatment. The RTPCR and western blots results from this study showed that the treatment with vitamin D3, melatonin and their combination could inhibit the proliferation of MCF-7 cells and caused apoptosis, by upregulating the $\mathrm{p} 53$ gene and protein expression. This study reiterated the use of vitamin D3 and melatonin as a promising adjuvant therapy for the treatment of breast cancer.

\section{Declarations}

\section{Authors' contributions:}

SHH,AbAA, contributed to the study design; the manuscript draft was prepared by NSA and SHH; reviewed and edited by AbAA, 
Ethical Approval and Consent to participate:

Not applicable

Consent for Publication:

All authors have read and approved for the final manuscript.

Availability of Supporting data:

All the data are available on request.

Declaration of competing interests:

The authors declare that they have no competing interests.

Funding:

The authors acknowledge the financial support of the Deanship of Scientific Research at King Saud University for funding this project (RG-1441-534).

Acknowledgments:

We are very grateful to the technical support and assistance of the Chair for Biomarkers of Chronic Diseases at King Saud University for carrying out this project.

\section{References}

1. Alotaibi RM, Rezk HR, Juliana Cl, Guure C: Breast cancer mortality in Saudi Arabia: Modelling observed and unobserved factors. PLoS One 2018, 13(10):e0206148.

2. Van Dycke KC, Rodenburg W, van Oostrom CT, van Kerkhof LW, Pennings JL, Roenneberg T, van Steeg H, van der Horst GT: Chronically Alternating Light Cycles Increase Breast Cancer Risk in Mice. Curr Biol 2015, 25(14):1932-1937.

3. Touitou Y, Reinberg A, Touitou D: Association between light at night, melatonin secretion, sleep deprivation, and the internal clock: Health impacts and mechanisms of circadian disruption. Life Sci 2017, 173:94-106.

4. Li Y, Li S, Zhou Y, Meng X, Zhang JJ, Xu DP, Li HB: Melatonin for the prevention and treatment of cancer. Oncotarget 2017, 8(24):39896-39921.

5. Al-Daghri NM, Al-Attas OS, Alkharfy KM, Khan N, Mohammed AK, Vinodson B, Ansari MG, Alenad A, Alokail MS: Association of VDR-gene variants with factors related to the metabolic syndrome, type 2 diabetes and vitamin D deficiency. Gene 2014, 542(2):129-133.

6. Ansari MGA, Sabico S, Clerici M, Khattak MNK, Wani K, Al-Musharaf S, Amer OE, Alokail MS, AlDaghri NM: Vitamin D Supplementation Is Associated with Increased Glutathione Peroxidase-1 
Levels in Arab Adults with Prediabetes. Antioxidants (Basel) 2020, 9(2).

7. Al-Daghri NM, Ansari MGA, Sabico S, Al-Saleh Y, Aljohani NJ, Alfawaz H, Alharbi M, Al-Othman AM, Alokail MS, Wimalawansa SJ: Efficacy of different modes of vitamin D supplementation strategies in Saudi adolescents. J Steroid Biochem Mol Biol 2018, 180:23-28.

8. Stambolsky P, Tabach Y, Fontemaggi G, Weisz L, Maor-Aloni R, Siegfried Z, Shiff I, Kogan I, Shay M, Kalo E et al: Modulation of the vitamin D3 response by cancer-associated mutant p53. Cancer Cell 2010, 17(3):273-285.

9. Jeon SM, Shin EA: Exploring vitamin D metabolism and function in cancer. Exp Mol Med 2018, 50(4):20.

10. Estébanez N, Gómez-Acebo I, Palazuelos C, Llorca J, Dierssen-Sotos T: Vitamin D exposure and Risk of Breast Cancer: a meta-analysis. Sci Rep 2018, 8(1):9039.

11. Gonzalo S: Novel roles of $1 \mathrm{a}, 25(\mathrm{OH}) 2 \mathrm{D} 3$ on DNA repair provide new strategies for breast cancer treatment. J Steroid Biochem Mol Biol 2014, 144 Pt A:59-64.

12. Cannell JJ, Hollis BW: Use of vitamin D in clinical practice. Altern Med Rev 2008, 13(1):6-20.

13. Maruyama R, Aoki F, Toyota M, Sasaki Y, Akashi H, Mita H, Suzuki H, Akino K, Ohe-Toyota M, Maruyama $Y$ et al: Comparative genome analysis identifies the vitamin $D$ receptor gene as a direct target of p53-mediated transcriptional activation. Cancer Res 2006, 66(9):4574-4583.

14. Liu D, Wang D, Wu C, Zhang L, Mei Q, Hu G, Long G, Sun W: Prognostic significance of serum lactate dehydrogenase in patients with breast cancer: a meta-analysis. Cancer Manag Res 2019, 11:36113619.

15. Granchi C, Bertini S, Macchia M, Minutolo F: Inhibitors of lactate dehydrogenase isoforms and their therapeutic potentials. Curr Med Chem 2010, 17(7):672-697.

16. Proietti S, Cucina A, D'Anselmi F, Dinicola S, Pasqualato A, Lisi E, Bizzarri M: Melatonin and vitamin D3 synergistically down-regulate Akt and MDM2 leading to TGF $\beta$-1-dependent growth inhibition of breast cancer cells. J Pineal Res 2011, 50(2):150-158.

17. Hou H, Sun D, Zhang X: The role of MDM2 amplification and overexpression in therapeutic resistance of malignant tumors. Cancer Cell Int 2019, 19:216.

18. Senturk E, Manfredi JJ: Mdm2 and tumorigenesis: evolving theories and unsolved mysteries. Genes Cancer 2012, 3(3-4):192-198.

19. Shangary S, Wang S: Targeting the MDM2-p53 interaction for cancer therapy. Clin Cancer Res 2008, 14(17):5318-5324.

20. Qin JJ, Nag S, Voruganti S, Wang W, Zhang R: Natural product MDM2 inhibitors: anticancer activity and mechanisms of action. Curr Med Chem 2012, 19(33):5705-5725.

21. Cucina A, Proietti S, D'Anselmi F, Coluccia P, Dinicola S, Frati L, Bizzarri M: Evidence for a biphasic apoptotic pathway induced by melatonin in MCF-7 breast cancer cells. J Pineal Res 2009, 46(2):172180. 
22. Thompson T, Andreeff M, Studzinski GP, Vassilev LT: 1,25-dihydroxyvitamin D3 enhances the apoptotic activity of MDM2 antagonist nutlin-3a in acute myeloid leukemia cells expressing wild-type p53. Mol Cancer Ther 2010, 9(5):1158-1168.

23. Cos S, Blask DE, Lemus-Wilson A, Hill AB: Effects of melatonin on the cell cycle kinetics and "estrogen-rescue" of MCF-7 human breast cancer cells in culture. J Pineal Res 1991, 10(1):36-42.

24. Mediavilla MD, Cos S, Sánchez-Barceló EJ: Melatonin increases p53 and p21WAF1 expression in MCF-7 human breast cancer cells in vitro. Life Sci 1999, 65(4):415-420.

\section{Figures}
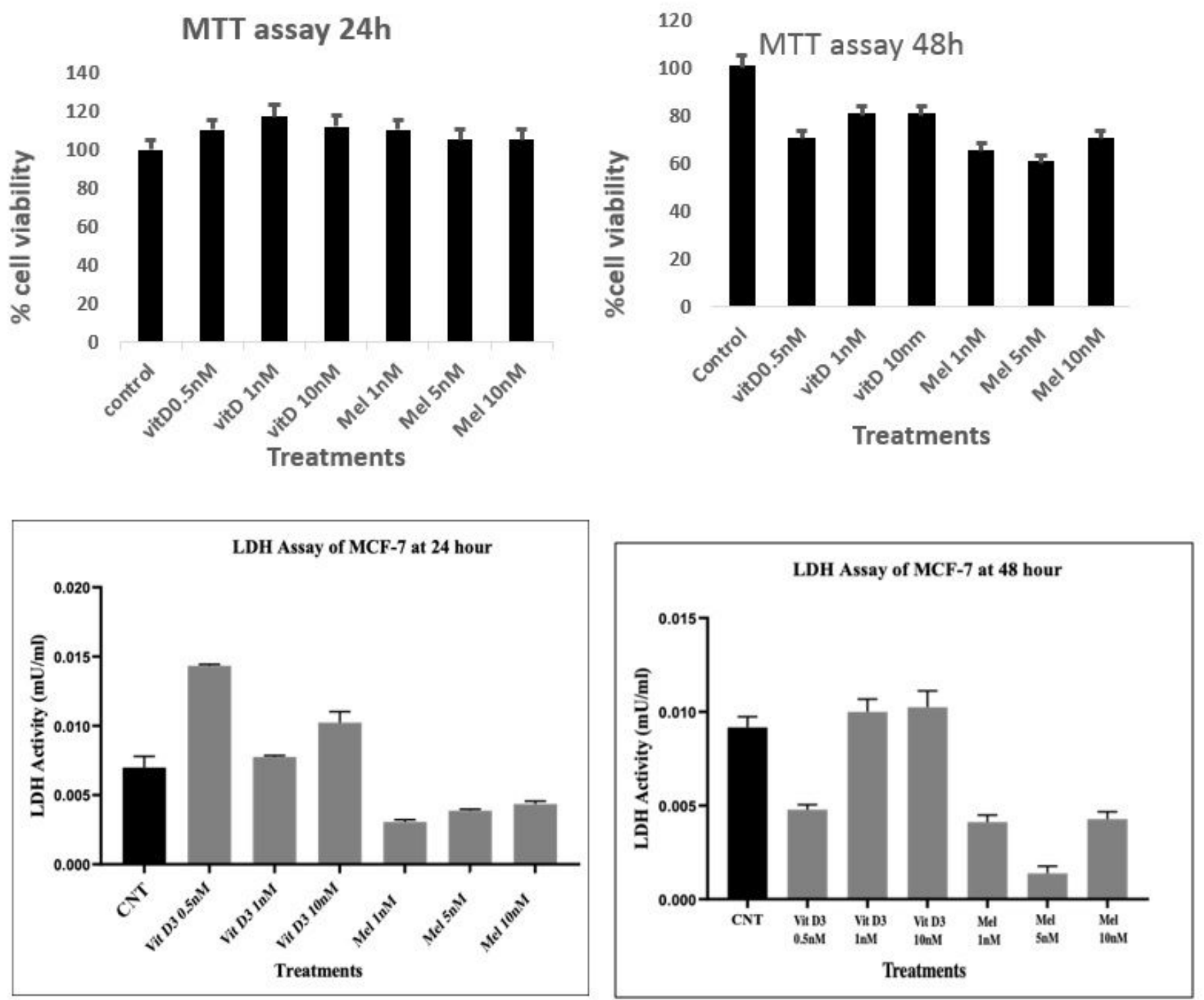

Figure 1

Effect of melatonin (MEL) on vitamin D3 (D3) on the cell viability of MCF-7 cells by MTT and LDH assay 


\section{P53 Gene Expression}

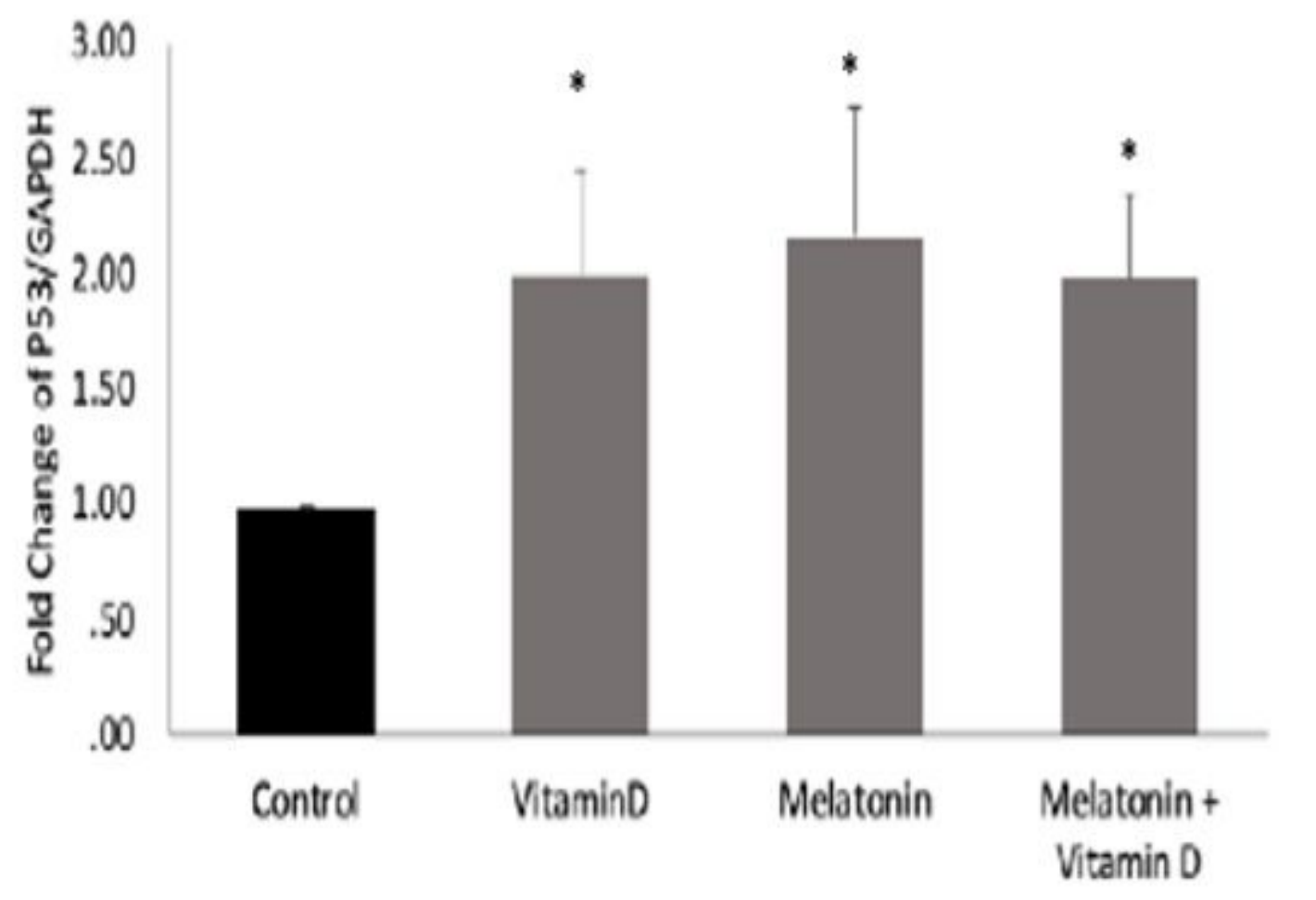

Figure 2

Relative gene expression of p53 in MCF-7 cell line. $\left(^{*}\right)$ indicate that the vitamin D3 treated and melatonin treated cells were significantly $(p<0.05)$ different from the control cells. 


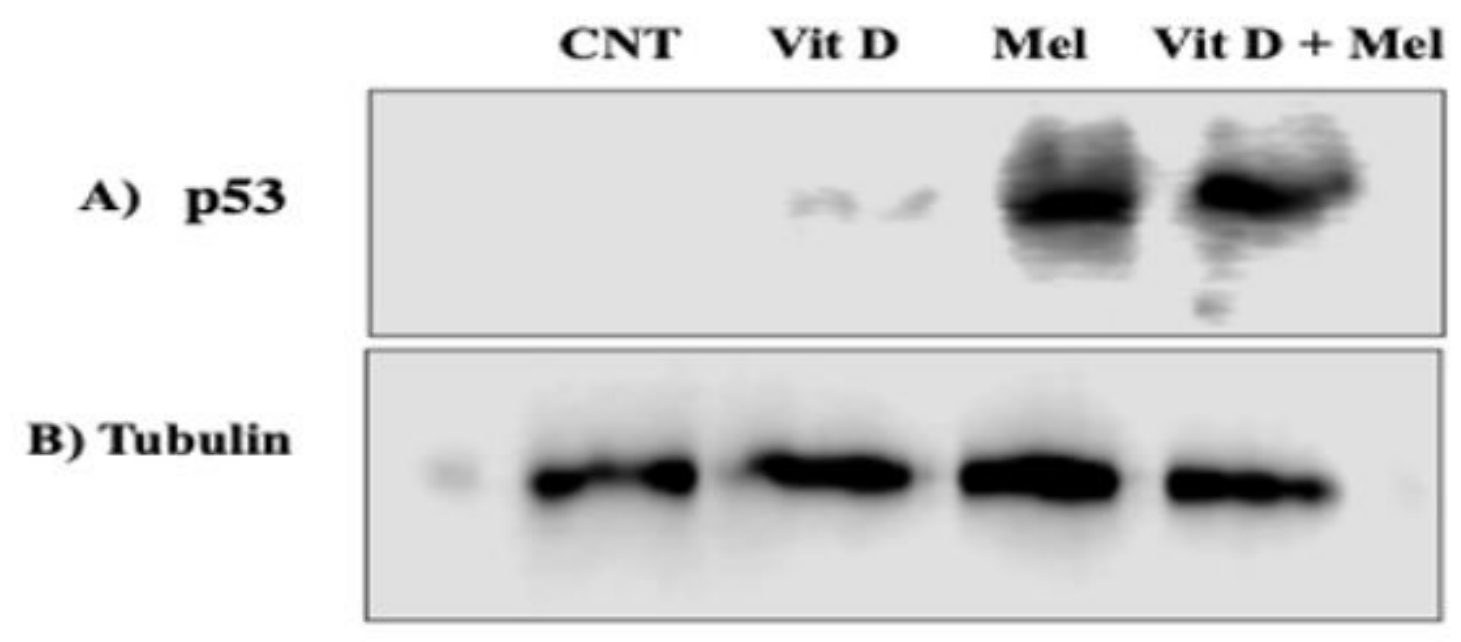

\section{p53 Protein Expression}

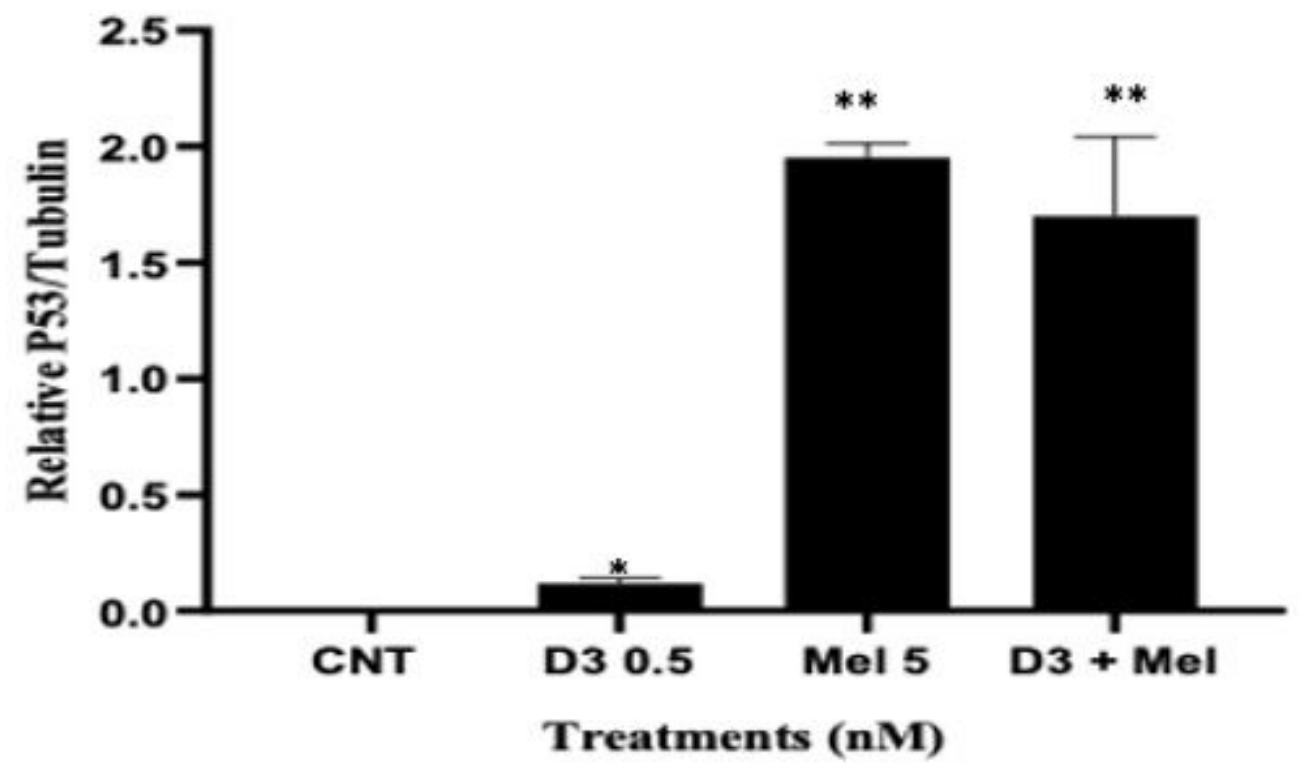

Figure 3

The effect of melatonin and Vitamin D3 on the protein level of p53. $\left(^{*}\right)$ indicate $\left.p<0.05 .{ }^{* *}\right)$ represent $p<0.001$. The protein expression of $p 53$ is significantly upregulated with both vitamin D3 and melatonin and their combined treatments. 